\section{The fartorian Bration}

oN

\section{THE STUDY OF STRUCTURE IN RELATION TO FUNCTION.}

Delivered before the Royal College of Phgsicians on Monday, October 19th, 1903.

By W. H. ALLCHIN, M.D.

Senior Physician, Westminster Hospital ; Fellow and Censor of the College.

[Dr. Allchin commenced his oration by quoting the terms of the decd by which Harvey founded the Harveian Festival, and in compliance with these terms referred briefly to the various benefactors of the College, and to some of those Fellows who by their labours had benefited mankind at large. He sketched Harvey's studies in anatomy, and then proceeded as follows :]

I propose to consider how far the ascertainment of the facts of structure as a necessary preliminary or adjunct to experimental methods has influenced the progress of biological knowledge, and what may be the limitations and extensions of the subject in that direction. But $I$ would guard myself at the same time from being supposed to assume that anatomy, however complete and precise, is of itself sufficient to furnish a physiology or knowledge of function, since in the earlier days to which I have referred, when the facts of gross anatomy were well and widely known, most erroneous and grotesque views were held as to the action and uses of the various organs; as, indeed, the history of the explanations offered for the circulation of the blood before Harvey's time sufficiently testifies. Nor do I fail to admit that much physiology, more especially in recent times, has become known even with considerable approach to exactness without a corresponding knowledge of its structural basis.

The Circulation.

The discovery and proof of the circulation, not only by the actual positive knowledge which it furnished but also by the methods by which it was arrived at, did much to dispel the fanciful and absurd views held as to the other functions of the body and thus became the starting point of modern physiology. But, as I propose to show by a few examples, the full benefit of Harvey's work, and, indeed, its applicability in explaining those other functions, was proportional to the extent of the accurate information possessed in respect to the structure of the organs by which these processes are carried out, and as fresh anatomical knowledge was forthcoming so did truer conceptions of the living activities develop from their observation and experimental investigation.

The Respiratory Function.

The rational study of the respiratory function, for example followed much the same course as did that of the circulation of the blood. The Galenic doctrine on this subject was that which Fabricius propounded in the lectures to which Harvey listened. The air which was introduced into the lungs by the "rough artery"-or as we call it trachea-was for the purpose of modifying and regulating the innate heat of the heart, of getting rid of the fuliginous vapours which resulted from this innate heat, and further with the object of being conveyed by the "vein-like artery"-pulmonary vein-to the left . side of the heart, there to generate those vital spirits which the arteries carried throughout the body. Although Harvey's discovery set aside at once and for ever such unintelligible nonsense as it had done the corresponding views of the heart's action, the time was not yet quite ripe for laying the foundation of sounder principles to the function of respiration. The state of knowledge of the anatomy of the lungs was scarcely so far developed in Harvey's time as was that of the structure of the heart, as may be seen in the Manuall of the Anatomy or Dissection of the Body of Man (enlarged 1642), by Alexander Read, who was a Fellow of this College as well as "Brother of the Worshipfull Company of the Barber Chirurgions."

Moreover, the significance of the movements of the chest in breathing and of their relation to the entrance and exit of the air from the lungs was but imperfectly realized. If to
Borelli may be attributed the first settlement of these questions on right lines, applying as he did to the problem the growing mechanical and chemical knowledge of his day, and showing as he did that the air entered the lungs as a result of atmospheric pressure as the chest enlarged by muscular contraction, and, further, that the air inspired was actually taken up by the blood, and that this was essential to the life of the animal, all of which are the facts which are at the basis of our present knowledge of the subject-if, as I say, Borelli showed this, the wav for his so doing was made clear for him by what had been done in explaining the true structure of muscular tissues, and still more by the labours of his fellow Professor at Pisa, Malpighi. More than fifty years after the invention of the compound microscope this observer applied it to the investigation of the tissues, and had himself informed Borelli of the minute structure of the lungs, how the terminal branches of the air tubes ended in closed vesicles on the walls of which the smallest blood vessels ramified, forming the communication between the arteries and veins, and thus supplying the completing link to Harvey's work within a few years after our great countryman's death. On such a foundation of exact knowledge the further pursuance of the subject was one for the physicist and chemist, and by them it has been brought to a high pitch, when once the nature of the machine they had to deal with was clearly defined. Observation and experiment were profitably occupied when anatomy had cleared the ground.

It was not only with the functions of respiration that Malpighi's great work on the investigation of tissue structure was concerned. His labours, added to and developed by the famous Dutchmen, Van Leeuwenhoek and Swammerdam, as well as by the Englishman, Robert Hooke, rendered possible the satisfactory examination of the other functions, though the difficulties of the necessary observation and experiment were greater than they were in respect to the circulation and respiration. Connected with the latter questions of a mechanical and chemical character arose more capable of being answered, as the sciences of physic and chemistry were at the time being better understood. While it was comparatively easy to see the movements of the heart and of the lungs in a living animal when these organs were exposed, vivisection did not render so clear the secretory activities of the glands, the changes brought about by digestion. the intricacies of tissue nutrition, and the workings of the nervous system. These physiological problems were more intimately connected with the living material, and were not so open to such observation or experimental inquiry as was then possible. And it may be said that less even was known of the structure of the organs concerned in these functions than there was of the circulatory and respiratory systems. But Malpighi and his fellows showed the way to what was wanted, and, as will appear, the uses and workings of the structures became open to scientific inquiry with important consequences.

Muscular Action.

Mention must be made, however, in further illustration of my theme, of what had been done to provide truer conceptions of the nature of muscular action. Up to the time of Vesalius, and even for some time afterwards, the contractile power of the muscles was regarded as resident in the connective tissue sheath of the fibres, the true muscle substances being looked upon as packing. Vesalius first indicated the proper rôle of this material, but it was not until more than a century later in 1664 that Nicolas Stensen, a Dane, described (1664-7) the structure of muscular tissue as he had studied it with the microscope, and thus furnished Borelli with the anatomical grounds upon which he formulated the principles of the action of this substance, also showing that the contractions were induced through the nerves. Although much that he taught was erroneous, being entirely dominated by mechanical conceptions of the nature of muscular contractility, the refutation of his errors showed the right lines, which was possible only on the structural basis which the microscope had supplied.

The most important step towards an understanding of the nature of muscular action was taken shortly afterwards by a Fellow of this College, Francis Glisson, whose name is more generally associated with his work on the liver and on rickets. In a treatise, however, published by him in 1673, De Natura Substantiae Energetica, he first explained the property of muscle substance which he called irritability, the character and phenomena of which were further developed by Haller nearly a century later. 
SECRETORY GLands.

Important as the work was that Malpighi did in respect to the discovery of the capillary blood vessels and the structure of the lungs, almost, if not quite, as great was that which he accomplished in connexion with the secreting glands. In earlier times the word "gland" had a wider range of meaning, and included such organs as the brain and tongue. That some of them were concerned in straining off certain serosities or humours from the blood was also generally held, but the active agents in the process were quite unknown, as would naturally be the case.when the intimate structure of the organs was hidden from view. To the nerves this function was often attributed, but the physiology of secretion was on a par with that of the heart or the lungs, with which of course it was interwoven. Within a few years previously to the time that Malpighi was investigating the structure of the skin, the liver, and the kidneys, the ducts of the pancreas and of the submaxillary and parotid glands were discovered and the position of these organs as secreting glands recognized. Malpighi in addition showed the lobular structure of the liver and the relation of the acini to the blood vessels, and showed the general course and arrangements of the renal tubules and of the glomeruli and capsules which were named after him. The instruments at his disposal did not permit him to realize the cellular constituents of these several orgens, but all these researches gave the death blow to the older conceptions as to the part played by the nerves in the secretory processes, and it was realized that the secretions were derived from the blood in its passage through the glands, and were passed into the commencements of the ducts. Stensen indeed, who had discovered the submaxillary duct, seems to have had a foreshadowing of the vasomotor influence on secretion.

The subject of digestion need not detain me, the problems with which it is concerned are so essentially chemical in nature that although in the latter part of Harvey's period, and within a few years after, the existence of the digestive juices as secretions of the various glands was known, their composition and mode of action on the food stuffs were not a matter of anatomical inquiry and depended for their satisfactory investigation upon a knowledge of chemistry that was developed, altogether outside the study of the living body.

The Nervous System.

Of all the functions of the body, none, it would be at once admitted, is more difficult of study or more obscure in the investigation than that of the nervous system. None also has been the subject of cruder description or wilder explanations. That this is so would seen natural, clearly associated as nervous phenomena are with the more recondite phenomena of life, and subject as their study has ever been to the influences of metaphysical speculation. At the same time, however, one, and as I conceive the most, important circumstance that has retarded the rational development of neurology has been the extreme difficulty that has existed in obtaining a precise knowledge of the actual structure of the organs which subserve the function. Even at the present day, great as are the advances that have been made, I think I should be correct in saying that less is known of the minute anatomy of the nervous centres than of any other organs in the body.

Whilst it may be said that with the present means at our command a knowledge of the histology of many of the tissues has reached or almost reached its limits, the precise disposition of the multiplicity of nerves and cells that constitute the brain and spinal cord as well as the ultimate termination of the nerve fibrils in the tissues and in the centres are yet to seek. Hence it is that whilst during the period of Harvey and immediately subsequent the study of the several functions to which I have referred began to emerge from the erroneous and fanciful notions by which they were surrounded and their investigation to be started upon lines that have been followed to the present day, the phenomena of the nervous system for some time remained enveloped in the mystic obscurity that had enshrouded them with growing intensity from the earliest times, an obscurity that was, if possible, made greater by the lengthy and unintelligible phrases in which they were described.

The main divisions of the brain were recognized-cerebrum and cerebellum, medulla, corpus callosum, corpora striata, ventricles, and even such smaller parts as the corpora geniculata, pituitary body, pineal gland, infundibulum, and septum lucidum. The distinction into white and grey matter was also appreciated, and that the former was made up of fibres was supposed. But the structural relation of the several parts to one another was very indistinctly realized and anything further as to minute structure was, of course, unknown. The following extract from Read's Manuall of Anatomy, already mentioned, will serve to show what was taught in a standard textbook, as we should now call it, concerning the functions of the brain.

Of the action of the brain. The action of the brain is this: After that the spirits and blood are discharged into the sinus of the dura materby the veines and arteries to temper the heat of them the brain is ordained (seeing it is colder than the heart) that the animall functions, wich are feeling and moving, may be the more readily executed. Wherefore the animall spirits seem not to differ from the vitall spirits in substance, but in qualities, namely, the temperament and attenuation, for they must be more temperate, because heat doth both tain the reasons (as we may see in drunkennesse and raving) and hindereth or preventeth the motion. The spirits ought also to be more subtile, because they are to passe like a thunder through the bodies of the nerves. So, as the vitall spirits are carried to the parts of the bodies by the arteries, so the animall are carried by the nerves. The animall spirits for this cause also ought to be subtill because the reasonable soul is resident in the brain, which doth contemplate thingsimmateriall, as Angels and it selfe.

Although this may be taken as illustrating the teaching of the day, and the work of Willis, De Cerebri Anatome (1659) was no advance thereon; there appeared ten years later (1669) a treatise on the anatomy of the brain by Nicolas Stensen, whose investigations on secretions have already been referred to, which foreshadowed in several respects many of the discoveries made and views held a century and more later. But the special feature of this treatise as bearing on my present subject is that after pointing out the extremely slight information possessed as to the essential structures of the nervous system, Stensen refused to admit, in face of the lack of all sound anatomical knowledge, any physiological deductions whatever. After pointing out a number of cases in which he shows that adequate anatomical knowledge is wanting, he says: "Whence you may guess how little trust is to be put in explanations based on such a futile foundation......I have said nothing of the use of parts, nothing of the actions which we call animal, since it is impossible to explain the movements carried out by a machine, so long as we remain ignorant of the structure of its parts."

It was only very gradually that this ignorance was cleared up, and pending that the progress of neurology was hindered by the mystical speculations of successive metaphysical doctrines. Until the discovery of the nerve cells and their connexion with the fibres was made no very sound notions on nervous function were possible.

The Development of Pathology.

Slowly and with many throwbacks as physiology emerged from obscurity and became established on a scientific basis the correlative subject of pathology long lagged behind in taking up a similar position. The reluctance, as it were, to regard morbid processes in the same manner as those manifested by a healthy organism was no doubt in part responsible for the delay in establishing any clear conceptions as to the nature of disease; but what was of far greater influence was the lack of any systematic observations on the appearances presented after death-anything that, in short, might be looked upon as a knowledge of morbid anatomy. Hence it was that the notions respecting disease and its workings were if possible more fanciful than those held in connexion with the healthy body, and were retained for long after the latter had been diverted on to right lines.

Although isolated records of necropsies were made from time to time ${ }^{2}$ it was not until the latter half of the eighteenth century that Morgagni laid the foundations of a scientific pathology by his work De Sedibus et Causis Morborum (1780), upon which a goodly superstructure was soon erected. "It stands most clearly revealed," says Virchow, " "in the history of pathology that the division of the body first into the larger regions-head, breast, abdomen, etc.-then into organs, then into tissues, and finally into cells and cell territories, was the first step which opened up to us the comprehension of disease." There is good ground for thinking that this comprehension would have been sooner grasped if the collection of records of post-mortem inspections which Harvey had made over many years had escaped the destruction which befell many of his papers when his house in London was ransacked during his absence at Oxford with King Charles.

The Development of Histology.

From this necessarily brief sketch of the development of physiology in relation to gross anatomy, it is apparent that 
any approach to an accurate understanding of the working of the several functions was only possible when the facts of structure were ascertained and appreciated; and that when these facts were scanty, fanciful and erroneous views were entertained as to the mode in which the corresponding functions were performed. With the prosecution of anatomical investigation beyond the range of the unaided vision the knowledge of the living organism and its working was by so much extended. The impetus given to the study of microscopic structure by the labours of Malpighi and his followers resulted in establishing histology - a term first used by Carl Mayer in 1820-as a specific branch of anatomical inquiry which has been pursued with ever-growing success to the present day, coincidently as the realm of gross anatomy became more and more restricted, so far as the human organism is concerned, by the very completeness of the knowledge of it.

Did time permit it would not be difficult to show, as indeed has in part already been done, that as the intimate structure of the tissues became revealed, so was the way cleared for a sounder physiology, whether by a more rational understanding of what observation and experiment had disclosed, or by indicating the direction in which observation and experiment might be fruitfully continued.

The progress of histological research has been marked by one great feature far reaching in its effects and of fundamental importance-the recognition of the cell as the tissue unit. And whilst this has served to give completeness to the views of tissue structure, and especially of the genetic relations of the several components of the organs, it served as a fresh starting point for the investigation of biological problems, since it was recognized that the life of the organism was but the life of the cell, differing only in degree of completeness; and the full realization of what is meant by specialization of function being dependent on differentiation of structure became apparent.

With entire appreciation of the complexity of the phenomena presented by the living cell, Brücke forty years ago affirmed that this must imply the existence of some structural arrangement in cell substance, some degree of organization, some further stage that had hitherto been detected in the disposition of the material which subserves function. Setting aside the obvious distinction into cell contents, nucleus, and attraction sphere, and the separation of the first into cell protoplasm and the metabolic products thereof (such as starch, fat, glycogen, and pigment granules), attention has been directed towards discovering in the apparently homogeneous protoplasm some evidence of structure.

Numerous observers long ago described a fibrillar arrangement in this material, a view that later gave place to the assertion that it is rather to be regarded as of a reticular nature, the protoplasm forming a network or meshwork. "the nodal points of which appear as individual granules." 4 The imperfect loculi formed by this disposition of fibrils were described as being occupied by a more fluid material. Objections were raised to this explanation, and the more recent description with which the name of Bütschli is associated attributes to the protoplasm a

foam structure, which depends upon the presence within a uniform ground mass of a large number of extremely fine vacuoles lying almost at the limit of microscopic visibility, and so close together that their walls consist of relatively thin lamellae. (Verworn.)

But, these and several other views as to the intimate structure of the living cell protoplasm which describe it "as being composed of two substances, one of which is disposed as a contractile net according to some, as a relatively rigid framework according to others, or as free filaments ; or whether it be built up of a more solid material and of a more fluid material which occupies the minute spaces or vacuoles which are hollowed out in the former"s have not met with universal acceptance, and there are still those who regard these relatively coarse indications of structure in cells as the results of post-mortem change or of fixing reagents. To such the living protoplasm is a homogeneous colloid, and its " peculiar and transcendental qualities are associated with molecular rather than with molar structure."

What is said as to the cell contents applies also to the nucleus, in which a reticular or meshwork appearance is described by some, as others would regard the actual living condition as one of perfect homogeneity.

In this uncertain state the question of the intimate structure of the living cell protoplasm must at present be left, so far as the 'same is capable of investigation by the microscope and its accessories. But, whilst fully recognizing that. with further improvements in method and in means this problem will be solved, it none the less seems certain, consistently with the present hypotheses as to the nature of the cosmos. that however far the eye may be able to penetrate there will still remain behind, and beyond a molecular or atomic structure, for the understanding of which other branches of scientific inquiry must be employed. "The organism," says Virchow, "is not an individual but a social mechanism. An exact anatomical analysis of this mechanism always brings us at last to cells; they are the ultimate constituents of all tissues as they were their origins, hence we call them the living elements, and hence we regard them as the anatomical basis of all biological analysis, whether it has a physiological or a pathological object in view. The cells are composed of organic chemical substances which are not themselves alive, but the mechanical arrangement of which determines the direction and power of their activity.'

Before proceeding to consider the next and chemical stage of structure, it would be well shortly to indicate some of the living phenomena which have either already received or still await their explanation in the intimate histology of the cell. Most important of these is contractility, whether this be manifested as irregular amoeboid movements, the rhythmic wavings of cilia, or the orderly and more highly differentiated contraction of muscular tissue. The ebb and flow of the more diffluent portions into and out of the reticulum of the spongio-plasm - the "streaming," as it has been termed-is a step towards explaining-apart altogether from the attempt to express protoplasmic movement in terms of inorganic phenomena, such as has been done-those alternate contractions and expansions of the bioplasm due to reciprocal rearrangements of its particles which constitute one of the most striking characteristics of the living organism.

The complicated changes connected with nuclear division, known as "mitosis," which underlie all cell multiplication, and hence are of such importance in growth and development, are only realized as the result of those microscopic investigations which have been directed towards discovering a structural organization of the cell itself.

The germ plasm and the problems of heredity connected therewith can only be discussed in terms of cell structure with any probability of satisfactory results. Possibly also the varied morphological characters presented by the fullydeveloped living constituents of the tissues, developed as they have been through successive stages from cells of almost identical appearance in the blastoderm, may be more fully understood when the atructure of their protoplasm is more accurately known. The so-called specificity of cells and its limitations-metaplastic interchanges-so important in the study of tumour formation, is an aspect of this same question.

\section{Biological Chemistry.}

From the earliest recorded times there has prevailed an idea which ascribed to matter an ultimate composition of indivisible, indestructible particles or atoms, and by no one was the atomic theory more firmly maintained than by the contemporary of the later years of Harvey-Isaac Newton. "To me," said he, "it seems probable that God in the beginning formed matter in solid, massy, hard, impenetrable particles of such sizes and figures, and with such other properties and in such proportion as most conduced to the end for which He formed them." By Robert Boyle, also, to whom natural philosophy in the seventeenth century owed much, the theory was held, though he found the explanation of chemical changes in the differences of atomic structure and arrangement of one single form of matter rather than of different elements-a crude foreshadowing of the present day conception by Sir William Crookes of the fundamental matter or "protyle." As is well known, however, it was not until the early years of the last century that the atomic theory received its practical development by John Dalton, since when it has remained at the foundation of physical and clemical science. "Despite attacks and criticisms," says Professor Clarke in his recent Wilde Lecture, ${ }^{7}$ "Dalton's generalization still holds the field; and from it, as from a parent stem, spring nearly all the other accepted theories of chemistry." The conception of an atom as the smallest conceivable portion into which an element can be divided, or that can enter into combination, and attaching to the idea of the atom a definite relative weight constant for atoms of the same element, but differing with different elements, gave a satisfactory explanation for the laws of definite proportions and of multiple proportions : which previously had been but incompletely recognized. 
Since with the exception of a few elementary gases an atom is always combined with one or more atoms of the same or of other elements, some term is required to denote the smallest portion of the substance capable of a separate existence, and for this the word "molecule" is employed. Built up on these fundamental ideas; there has developed among other great generalizations the chemistry of the carbon compounds and the hypothetical recognition of the relative arrangements of the atoms within the molecule-in short, chemical constitution or: chemical structure. Now "the greater the valency of an element the more complicated are its combining ratios, and the greater the possibility of its atoms forming numerous compounds with similar and dissimilar atoms." The atoms of carbon, which is the chief element in so-called organic .bodies, "possess, in a much greater degree than those of any other element the property of combining with similar atoms, whereby a part of their valencies are satisfied." 8 Thus may be formed groups of carbon atoms so linked together that their valencies are in part satisfied among themselves, constituting what are known as carbon nuclei; and the free valencies being satisfied by atoms of other elements, molecules are formed in which much energy is accumulated with more or less instability.

Such conceptions as to the fundamental nature of matter, of its molecular structure and arrangement of atoms therein, permitted the laying down of rational or structural formulae for chemical compounds; and when the further suggestion was made of linking the atoms in tridimensional space rather than in a single plane, a still further extension of the idea of the atomic disposition within the molecule became possible, and "stereo-chemistry was born" (Clarke).

With theories of this kind ready at hand-theories which had done and are still doing so much to explain the: phenomena met with in the domains of physics and chemistrywhat more natural than that the biologist, recognizing that but little progress was being made in the further investigation of the intimate cell structure, and that the histologist in point of fact was apparently at the limit of his range of observation, should turn to the physico-chemical sciences for the satisfaction of his quest?

The attempts, however, from the chemical side to explain the constitution of living matter-due, no doubt, to the extreme complexity of the subject-cannot beisaid as yet to have led to any very definite result, although several very suggestive hypotheses have been put forward. Inasmuch as no empirical formula has up to the present been constructed for any one of the typical proteids, a rational or structural formula for the constitution of the undoubtedly large molecules of which these substances are composed is scarcely to be expected; and this, although necessary, is only the first stage in the inquiry. Analysis of proteid bodies give rise to numerous products; the end substances, such as carbonic acid, water, and urea, we are familiar with, but the intermediate ones "fall into two principal groups, the fatty compounds (generally containing an amidogen radicle) and the aromatic compounds or derivatives of benzene." ${ }^{2}$. Accurate as further work in this direction may become, however, it still of necessity will not be a satisfactory explanation of the composition of living protoplasm, which is ever - in a state of flux, the continuous decompositions and reconstructions of which underlie its activities and are indeed phases of its living. Hitherto all attempts to ascertain the composition of the bioplasm have resulted in killing the material, and hence the solution of the question is evaded. And although proteids are obtained from living protoplasm, there is no proof that they exist as such in the living matter, but rather are they the dead derivatives of what is killed in the process of examination.

Theories of the constitution of proteids arrived at by the attempted synthesis of these substances have been provisionally set out, and though no one of them is free from objection, it may reasonably be supposed that consistent with prevailing chemical theories they are on the right lines. Among these should be mentioned that propounded by our distinguished Fellow, Dr. Latham, according to which what he terms "living proteid" is composed of a chain of cyanalcohols and $a$.thio-alcohol united to $a$ benzene nucleus. These cyan-alcohols are exceedingly unstable and prone to undergo intramolecular changes, properties also possessed in a marked degree by bioplasm, and similar bodies are obtained from the disintegration of both cyan-alcohols and proteids. A more recent attempt in the same direction has been made by Verworn; ${ }^{10}$ who describes the "biogens," as he terms them, as real chemical and physical entities, each consisting of a benzene nucleus round which are arranged various groups of atoms, the idea being arrived at by a study of the metabolic products of the organism. The extreme liability of the biogen Verworn attributes to the incorporation of oxygen in the molecule, the absence of which; rather than the accumulation of waste products, he regards as responsible for the cessation of the irritability of the bioplasm. It may be further observed that it is in the cell protoplasm and not in the nucleus that this observer locates the biogens.

Whilst fully realizing the purely speculative character of these coneeptions, the provisional use that they may be in comprehending the activities of the living organism is apparent. For many of these complex processes the knowledge of the chemical anatomy of bioplasm is as essential as the gross anatomy of the organs concerned is for an understanding of the circulation of the blood. As the chemist and the physicist find in the atomic theory and its developments an explanation of the properties or functions of the nonliving bodies with which they deal, so may the physiologist find in the same assumptions a clue to those even more abstruse functions displayed by living materials, and furnish to the pathologist and to the clinical physician those data upon which a fuller realization of morbid processes may be obtained and sounder principles for their prevention or theiv treatment be laid down.

Where in the whole range of physiological inquiry is to be found a region into which the observer has less penetrated, and where for the want of some guidance he is more adrift in the comprehension of what he does recognize than in the complicated region of "nutrition?" And yet how: essential for the mere framing of a proper dietary, or for an understanding of the protean symptoms collectively denominated "gout," is it that we should be able to form some idea of what becomes of the absorbed food stuffs, when having undergone some elaboration in the epithelial cells, the hepatie tissues, and the blood through which they have passed, they come "within the sphere of influence" of the living cell. What, too, is more important than to be able to attach to the comprehensive term "metabolism" some rational meaning, based upon a knowledge of what actually occurs, and what structural arrangements and rearrangements take place within the bioplasm of the tissues? The practical importance of this must be obvious and should prevent the relegation of such questions as I have been discussing as transcendental and of no useful purpose.

One of the greatest and most far-reaching advances in pathology within recent years is undoubtedly the recognition of the part played by micro-organisms in the causation of disease. But the full value of the knowledge gained is not comprised in the detection and cultivation of the specific bacillus nor yet even in the discovery of the particular toxin which the microbe produces, important as such information is. We require to know how and why these poisons affect the tissues as they do, and in order to arrive at that the rational formulae of these poisons must be known -and, what is more, the molecular structure of the living cells upon which the noxious material acts-ere we can realize how by some untoward substitution in the atomie arrangement of the living : molecule its activities are :prejudicially affected.

Our treatment of disease by drugs has been forcibly if irreverently described as " pouring substances of which we know little into bodies of which we know less." Pharmacology has done a little towards removing this reproach, and that department of it which deals with the rclation between the chemical composition and constitution of a substance and its physiological action no doubt lies at the root of all rational drug therapeutics. But no one can assert that se far very much is known in this direction or that there has been much practical outcome of the investigations. This would be quite otherwise, however, if we had a knowledge of the molecular structure of living matter which would show the perversions taking place in disease and indicate the way in which they could be corrected.

The subject of immunity may reasonably be expected to find its interpretation in the ultimate constitution of the tissue elements; as also those at present vague conditions which we are dimly conscious of, represented by such terms as "bodily constitution" and " temperament." So, too, the differences in response on the part of different individuals to the same morbific influence, the variations : in the manifestation of what we speak of as the same disease in various persons that lead the sagacious physician to treat the patient and not the malady; and in brief those intangible charactaps 
which determine the responsibility of the organism for morbid symptoms, as distinct from the injurious agent that we speak of as cause, each and all await their explanation. The factors of the environment which condition the vitality of the tissues are not to be found solely in such external conditions as are commonly comprised in that expression.

As illustrating these environmental relationships may be mentioned the various forms of taxis or tropism whereby the direction of the movements exhibited by living protoplasm may be influenced. The best known of these is "chemotaxis" as met with in connexion with some states of leucocytosis, but it is probable that other forms of taxis saused by pressure, gravity, heat, and light also prevail. "The spermatozoon seeks the ovum, and almost everywhere in the living world is led in the right path by the chemotactic action which the metabolic products of the egg-cell exert upon the freely moving sperm-cell.

Every species of spermatozoon is chemotactic to the speeific substances that characterize the ovum of the corresponding species." (Verworn General Physiology.) The effect also of these external agencies as well as others like moisture and the density of the surrounding medium on the nutritional activity and on the power of reproduction as well as on the motility of the simplest organism has been experimentally demonstrated; suggesting a chemical complexity of protoplasmic structure which is open to disturbance by the external world

The behaviour of cell to cell, their mutual interactionscytotaxis-and their physiological resistances the one to another will have to be taken into account in forming any thorough conception of the totality of life, whether healthy or diseased, that an organism presents, and the understanding of such problems cannot be attained until the finite structure of the material concerned be rendered plain, or be assumed with such justification as those concepts underlying physico-chemical action at present furnish.

As bearing upon these and other questions a very large body of experimental evidence exists to show that there are great varieties in protoplasm, and that it is far from being of a uniform character in all cases as was formerly supposed, and this even amongst the simplest unicellular organisms. The differences in behaviour exhibited by different species in response to various reagents clearly demonstrate this. For whilst some are so profoundly affected in their molecular constitution as to succumb on being subjected to certain poisons, others, in no wise differing so far as can be determined by the means at present at our disposal, are quite uninjured. Some kinds of bioplasm appear to have a general high resistance to all chemical agents, while others have a high or low resistance to particular agents only ; thus, nervous tissue, for instance, is readily and injuriously affected by substances (for example, cocaine or nicotine) to which many protophyta are indifferent. Since also many toxic bodies which produce no effect upon dead albumen are yet violently poisonous to living protoplasm it would seem probable that the latter contains in its construction certain unstable groups of molecules which undergo replacement by others from the toxic agents. All this goes to show that protoplasm is extremely complex and consists of numerous kinds of compounds, many of which are very unstable. Also that not all protoplasm contains the same compounds, but that these are dissimilar in different organisms. And, further, that not all of the compounds in any protoplasmic body are essential to life, and that we may so act on a protoplasmic body by a weak reagent and gradually change its composition so that it will no longer be killed by a strong solution of the same reagent, thus affecting an acclimatization, or, as we should say, rendering the organism immune. 11

May it not also be in this same molecular structure of living matter that will be found the explanation of those phenomena of development and of organic evolution by which the fertilized ovum of two different kinds placed under identical conditions will each attaiu " to such form and structure as best fit it for its place in Nature-processes which cannot be measured or observed by the same methods as are used in the investigation of the phenomena of non-living nature - that is, by measurements of their time and place relations under varying conditions - in other words, by the method of experiment," 12 which are applicable to other processes of living organisms? "The biogen hypothesis gives a plausible account of growth and the production of fresh living material by supposing that the molecule is capable of polymerization-that is, the union of a number of molecules to form a single molecule-and then of falling into simpler substances once more." 13

Surely I need not plead for the importance of these questions I have set out, an importance that is not merely the eoncern of the biologist, but is that of the practical physician. In the solution of these problems lies widespread benefit to mankind.

\section{The Constitution of Matter: Radio-Activity.}

Yet one step further. 'The atomic theory of the constitution of matter and its developments, although they have hitherto sufficed for the needs of the chemist who concerns himself with the decompositions and reconstructions of substances, is not the last word for some at least of the most progressive physicists. Is the atom indivisible and finite? has ever been a question that even the most pronounced atomists have asked themselves from time to time, and if the explanation of the recent discoveries that have been made in connexion with radio-activity be correct the answer must be in the negative. Briefly to summarize from this year's Romanes lecture by Sir Oliver Lodge the most advanced views that physicists are inclined to hold, it may be said that the atom is conceived as consisting of an aggregate of what have been termed corpuscles, and further that each atom may have associated with it a definite charge of electricity, atoms of different kinds having multiples of this charge, such an electrically charged atom being termed an "ion." Now the smallest unit of electric charge which itself "possesses the most fundamental and characteristic property of matter, namely, mass or inertia "is known as an "electron," and the charge with which the atom is possessed consists of a number of these electrons. When the ion contains an equal number of positive and of negative electrons it is electrically neutral, but when there is an electron in excess it is called a negative ion (cation) as one containing an electron in defect is a positive ion (anion). The latter, however, has not been recognizcd. Within the atom the "electrons are in a state of vigorous motion among themselves." But it has been found that the electrons can be detached from the atom at an electrode, and such isolated particles form the cathode rays which, when stopped suddenly by a massive obstacle, give rise to the so-called Roentgen rays. Hence the electron " is the most definite and fundamental and simple unit which we know of in Nature." Whether, however, the electron is to be considered as solely consisting of electrical charge or whether this be associated with a material particle is a moot point. Some hold that the latter is non-existent, and that in place of there being two kinds of inertia which we speak of as material and electrical the latter alone exists, the atom therefure being "composed solely of electricity." Such a concept of the electrical nature of matter is obviously a more precise expression of the monistic theory, in accord with which matter and energy are but convertible terms. Such a hypothesis suggests also that the various elements as we know them are but " different groupings of one fundamental constituent," the atom of each one consisting of its own special number of electrons; the unity of matter being thus arrived at.

Highly speculative as such considerations are, they nevertheless find support in electrical phenomena, and still further in radio-activity, of which we have heard so much in connexion with radium and allied substances. This radioactivity "consists in the flinging away with great violence of actual atoms," which exceed in their rate of movement the fastest cannon ball ever projected. The substance left is also radio-active, and successive residues, differing as they do from each other, yet continue to exhibit radio-activity, "and one of the residues so left seems ultimately to pitch away electrons simply instead of atoms of matter"-a veritable transmutation of matter. Thus it is supposed that "the massive and extremely complex atoms of a radio-active substance are liable to get into an unstable condition........ and gradually disintegrating, fall into other and ultimately more stable forms of matter." Yet it appears that as the radio-active substance thus breaks up fresh radio-active matter is as constantly regenerated, possibly, as Lord Kelvin has suggested, from the ethereal waves surrounding the atoms.

Even as the atomic and molecular theory was laid hold of to furnish an explanation of that flux of chemical activity which we denominate bioplasm, so have these further speculations on ionic action been pressed into the same service and with some promise, wholly hypothetical as they may be. It is to Professor Loeb, of Chieago, that we in the main owe the application of the ionic theory to physiological phenomena. "The bulk of protoplasm," he writes, "14 "consists of colloidal material, and the physical manifestations of life such as muscular contraction, protoplasmic motions, and the innervations are due to changes of the condition of these colloidal solutions. And the reason why the electrical current is the universal form of stimulation is that the particles in colloidal solutions are electrically charged, and that every alteration of the charge of the particles will result in a process of innervation, or a contraction, or a protoplasmic motion." Thus nerve action is simply electrical action, negative ions being released where nerve blends with muscle, or where systems of concatenated neurons come into connexion. Ion after ion is precipitated, and thus neural conduction takes place. ${ }^{15}$ This play of ions is ex $\cdot \cdot$ ited or inhibited by the character of the fluids with which the protoplasm is 
bathed, by the nature; that is, of the ions which these fluids contain.

Most effective in stimulating protoplasmic action are such substances as sodium salts, as those of lime restiain it, and since such inorganic bodies are among the products of tissue waste it may be that in the ions of metabolism are to be be found the causes of that rhythmic tendency to activity which nerve cells and muscle fibre alike exhibit. If normal neuro-muscular action may be thus induced, the theory offers a clue to the comprehension of some of the most obscure morbid manifestations of these tissues, for, says Professor Loeb :

That certain ions are capable of bringing about forms of irritability in nerves and muscles which do not exist normally may perhaps furnish the explanation of a certain number of morbid phenomena (neurosis and hysteria) in which the motor and sensory reactions of the patient are modified.

\section{CONCLUSION}

In thus labouring as it may seem the successive phases of structure from the grossly obvious to such as the microscope discloses, and thence to the hypothetical chemical and electrical constitution of the material involved, it is not for a moment claimed that the investigation and the observation of functional manifestation have waited for anatomical discovery. In many departments of physiology, notably in that concerned with nerve and muscle and with secretion, a large mass of information has been acquired as the result of carefully-devised experiments, whilst but little has been done towards ascertaining the ultimate structure of the tissues concerned-little, that is, beyond what was known a score of years ago or more. But in respect to such tissues as these microscopic examination would seem almost to have reached its limits, and for the complete comprehension of the physicochemical phenomena more recently ascertained the problem of the chemical and electrical constitution of the muscle or nerve fibre and of the gland cell awaits solution. Though it may be true that " it is quite impossible to attain to a complete knowledge of function without a thorough anatomical analysis" (Huxley) - and this, it may be added, although the observation of function may have led to the study of structure -yet it is clear that "structure" must include a wider range of meaning than hitherto it has been commonly thought to bear, and to reach into those regions where observation is conditioned by speculation, and where theory has to take the place of demonstrable fact. However true it may be that for a general conception ot the physics of the circulation Harvey was beholden to his anatomical knowledge, it is also true that for our later acquired information of the share taken in the movement of the blood by the arteries an acquaintance with the -structure of these vessels is necessary, whereby their elasticity and their tone are referred each to its own tissue.

The problem that Harvey solved was one that in its broad features was a mechanical one; but it does not end with such information as the gross anatomy of the organs and the histology of the tissues supply. Behind it lie the contraction of the muscular substance of the heart and arteries and the nervous governance of that material, which involve considerations of another character. For the complete understanding of the electrical and chemical changes which are associated with the passage of the nervous stimulus and the muscular response we should require to know what are the underlying molecular rearrangements and alteration in chemical constitution crudely represented by the formation of certain waste products. At this point, I say, precise knowledge fails us, and we turn for assistance to theories whioh have been so helpful in the explanation of the properties of non-living matter, consistent therein with the principle laid down by Mayer half a century ago "to refer both vital and physical phenomena to a common measure."

Whilst I have endeavoured to illustrate with such completeness as my brief time permits the relationship of physiology to anatomy, whether normal or morbid, the general tenor of my remarks will have indicated that when the limits of visibility, even with our most perfect instruments, have been reached, the separate investigation of structure and of function no longer becomes possible. The molecular constitution, chemical or electrical, of living matter becomes conceivable only in terms of action, and function and structure are but aspects of each other.

No deeper secrets of Nature exist to be searched out by observation and experiment than these and none will more benefit mankind in their discovery. To their investigation, therefore. in obedience to the precept of Harvey, no I exhort you to tuin.

\section{REFERENCES.}

1 Lectures on the History of Physiology during the Sixteenth, Seventeenth, and Eighteenth Centuries, by Sir M. Foster, rgor. 2 Bopetus in 1675 had collected many such in his Sepulchretum. 3 Huxley Lecture delivered at Charing Cross Hospitai, October 3rd, 1898. 4 General Physiology, by Professor Max Verworn, translated by 'F. S. Lee. Ph.D., "1899. 5 The Structure of Cell Protoplasm, by W. B. Hardy, Journal of Physiology, 1899, vol. Xxiv, p. 159. '6 Huxley Lecture. 7 Delivered May rgth. 1903, to the Manchester Literary and Philosophical Society on the occasion o the Dalton centenary celebrations. 8 Principles of General Organic Chemistry, Professor Hjelt, 18go. 9 Halliburton in Sohäfer's Textbook of Physiology, vol. i. p. 35. 10 Die Biogen-hypothese, 1903; see also Nature February 26th, 1903. 11 Experimental Morphology, by Dr. Davenport, 1897. 12 Sir J. Burdon Sanderson, Times, May I1th. I903. 13 Nature, loc. cit. , Medical Journal. March 22nd, rgo2.

SEVENTY-FIRST ANNUAL MEETING of THE

\section{British Altedical Assoriation.}

\author{
Held in Swansea, July 28th, 29th, 30th, ad 318t 1803.
}

PROCEEDINGS OF SECTIONS.

SECTION OF MEDICINE.

Sir Isambard Owen, M.D.; F.R.C.P.; President.

\section{DISCUSSION ON \\ MEDICAL INFLAMMATIONS IN THE CAECAL REGION.}

I.-Paul M. Chapman, M.D., F.R.C.P., Physician, Hereford General Infirmary.

Dr. Chapman, in introducing the subject, discussed the position of the physician with regard to the treatment of inflammations in the caecal region. The responsibility of advising operation should depend more largely on the physician, and he sympathized greatly with the position of the general practitioner, who often said such and such a surgeon had seen his case and had recommended operation, the practitioner himself begging the physician to put his' foot down and discountenance any such thing. In many cases perhaps in most mild cases, through appropriate treatment known to all, such inflammations would entirely subside. He thought the physician should have more authority and that surgeons should not take upon themselves the entire responsibility of advising abdominal section. Such advice should come from the physician, who really could not evade his responsibility.

\section{II.-Henry W. King, M.D., M.R.C.S., Physician, Chester General Infirmary.}

DR. KING said: Inflammations in the caecal region divide themselves into the acute (generally appendicitis cases) and the subacute (generally caecal cases proper). The former I feel certain are best treated by expectant non-operative methods. In the majority of these, where the pain is not so excessive as to indicate perforation or gangrene of the appendix tip, the patient with a pulse of 100, temperature ${ }_{102}^{\circ}$, vomiting and pain, my custom is to give nothing but water by the mouth in very small doses, even so little as a teaspoonful every quarter of an hour for the first 12 hours or so, and give opium and belladonna in large doses at once the results in these cases are generally very good. In the subacute form with a history of constipation I prescribe either an aperient with rapidly following doses of belladonna or enemata with hot fomentations.

III.-T. D. SAvilL, M.D., M.R.C.P.,

Physician, West Find Hospital for Diseases of the Nervous System, and Hospital for Diseases of Skin, Leicester Square.

Dr. SAvill considered that the treatment of appendicitis was preventive, remedial, and surgical. An important part of the preventive treatment of appendicitis was the treatment of chronic catarrhal colitis, occasionally of a membranous type, and in many cases associated with neurasthenia. This was chiefly irrigation, particularly with a weak solution of chinosol or silver nitrate. As regarded appendicitis, if the patient's pulse were under 100 or the temperature not raised he would temporize in operation. Opium should be with- 